Como citar: Souza, D. C. de, Honorato, E. J. S., Beiras, A. (2021). Discriminação contra homossexuais no mercado de trabalho: revisão da literatura. PSI UNISC, 5(1), 127-143. doi: 10.17058/psiunisc.v5i1.15452

\title{
Discriminação contra homossexuais no mercado de trabalho: revisão da literatura
}

\author{
Discriminación contra homosexuales en el mercado laboral: revisión de la literatura
}

\author{
Discrimination against homosexuals in the labor market: literature review
}

\author{
Daniel Cerdeira de Souza \\ Universidade Federal de Santa Catarina (UFSC), Florianópolis - SC/Brasil \\ ORCID: 0000-0002-2446-8244 \\ E-mail: dancerdeira01@gmail.com
}

Eduardo Jorge Sant'Ana Honorato

Universidade do Estado do Amazonas (UEA), Boca do Acre - AM/Brasil ORCID: 0000-0003-4706-0185

E-mail: eduhonorato@hotmail.com

Adriano Beiras

Universidade Federal de Santa Catarina (UFSC), Florianópolis - SC/Brasil ORCID: 0000-0002-1388-9326

E-mail: adrianobe@gmail.com

\begin{abstract}
Resumo
O trabalho é central na organização da vida em sociedade, mas o acesso ao mercado e a permanência no emprego possuem atravessamentos que vão além de questões econômicas. Nesse sentido, o objetivo deste foi analisar a literatura sobre a discriminação vivenciada por homossexuais no mercado de trabalho. Metodologicamente, foram analisados 12 artigos colhidos do Portal Periódicos CAPES, publicados entre 2014 e 2019, que foram analisados em dois momentos: primeiramente de forma descritiva através da elaboração de um instrumento de pesquisa e após, a partir da Análise de Conteúdo. Os resultados foram compilados em 6 categorias, sendo: 1) Formas de Discriminação; 2) Discriminações interseccionadas; 3) A identidade homossexual; 4) Remuneração; 5) Profissões específicas para gays e lésbicas; 6) Inclusão e políticas de gestão da diversidade, que discutiram que homossexuais são expostos a diversas formas de discriminação no mercado de trabalho, o que piora quando o homossexual não performatiza o gênero tido como natural para o seu sexo. As políticas de gestão da diversidade funcionam muito mais como uma forma de melhorar a imagem da empresa na sociedade do que uma forma de criar um ambiente de igualdade de oportunidades.
\end{abstract}

Palavras-chaves: Homossexualidade; Mercado de trabalho; Gênero; Discriminação; Emprego.

\section{Resumen}

El trabajo es fundamental para la organización de la vida en sociedad, pero el acceso al mercado y la permanencia en el empleo tiene intersecciones que van más allá de las cuestiones económicas. En este sentido, el objetivo de este estudio fue analizar la literatura sobre discriminación experimentada por los homosexuales en el mercado laboral. Metodológicamente, fueron estudiados 12 artículos recopilados del Portal Periódicos CAPES, publicados entre 2014 y 2019, analizados en dos momentos: primero de manera descriptiva por medio de la elaboración de un instrumento de investigación y luego, desde el Análisis de Contenido. Los resultados se compilaron en 6 categorías: 1) Formas de discriminación; 2) discriminaciones interseccionadas; 3 )
La identidad homosexual; 4) Remuneración; 5) Profesiones específicas para gays y lesbianas; 6) Inclusión y políticas de gestión de la diversidad, que discutieron que los homosexuales están expuestos a diversas formas de discriminación en el mercado laboral, lo que empeora cuando el homosexual no realiza el género considerado natural para su sexo. Las políticas de gestión de la diversidad funcionan mucho más como una forma de mejorar la imagen de la empresa en la sociedad de que crear un entorno de igualdad de oportunidades.

Palabras clave: Homosexualidad; Mercado de trabajo; Género; Discriminación; Trabajo. 


\begin{abstract}
The profession/occupation is central to the organization of life in society, but access to the market and permanence in employment have junctions that go beyond economic issues. This study's objective was to analyze the literature on discrimination experienced by homosexuals in the labor market. Methodologically, 12 articles collected from the Portal Periódicos CAPES were published between 2014 and 2019, which we analyzed in two moments: first in a descriptive way through the elaboration of a research instrument and then, using the Content Analysis. The results were compiled in 6 categories: 1) Forms of Discrimination; 2)
\end{abstract}

intersected discriminations; 3) The homosexual identity; 4) Compensation/payment; 5) Professions specific to gays and lesbians? 6) Inclusion and diversity management policies discussed that homosexuals are exposed to various forms of discrimination in the labor market, which worsens when they do not perform the gender considered natural for their biological sex. Diversity management policies work much more to improve the company's image in society and do not create an environment of equal opportunities.

Keywords: Homosexuality; Labour market; Genre; Discrimination; Job.

\section{Introdução}

De maneira geral, o trabalho ${ }^{1}$ possui um aspecto central na organização da vida do sujeito. Por meio dele obtém-se oportunidades de construir sua identidade, ter suporte social, encontrar um propósito ao qual valha a pena se dedicar, despender tempo de modo relevante, encontrar desafios, adquirir status, obter renda, etc (Zanelli, Calzaretta, García, Lipp, \& Chambel, 2010), mas também envolve questões para além da subsistência material, pois mesmo se fosse obtido recurso para viver confortavelmente pelo resto da vida, muitos ainda continuariam trabalhando, ainda que sob aspectos e condições diferentes, por motivos como: sentir-se útil, evitar o vazio existencial e ter um objetivo ou causa considerada válida na vida (Silva \& Tolfo, 2012).

O trabalho possui, então, extrema relevância para motivação e satisfação das pessoas, constituindo-se em atividade exclusivamente humana direcionada para uma finalidade. Um conjunto de ações com um significado próprio de transformação do homem e da natureza, dependendo de questões pessoais e sociais (Pereira, Del Prette \& Del Prette 2008), podendo ser fonte de felicidade, saúde e auto-realização humana, implicando em encontrar propósitos válidos que confiram sentido à existência humana nos planos de vida pessoal (Silva \& Tolfo, 2012), quanto pode também ser fonte de adoecimento (Martins \& Pinheiro, 2006).

Entendendo a dimensão e importância do trabalho no contexto social, com um olhar mais atento, podemos observar que o acesso e permanência no mercado de trabalho pode não ser dado em condições de equidade a todas as pessoas. Há determinados grupos sociais que têm o acesso dificultado ao mercado de trabalho e quando o conseguem, as experiências vivenciadas nesse contexto podem não ser das mais agradáveis, dentre esses grupos, destacamos as pessoas homossexuais. Nesse sentido, o objetivo deste estudo foi analisar a literatura publicada no formato de artigos científicos sobre a discriminação contra homossexuais no mercado de trabalho.

Rubin (2003) discute que o sistema sexo/gênero serve como um dispositivo para controlar e disciplinar a organização social. Com isso, o mesmo pode funcionar como uma tecnologia que auxilia a subordinação de homossexuais aos heterossexuais a partir da heteronormatividade, que é definida por uma norma compulsória à heterossexualidade, estando apoiada na ligação linear entre sexo, gênero e expressão da sexualidade (Louro, 2000). Nessa perspectiva, a partir dos sexos biológicos (macho/fêmea) se convencionaram

\footnotetext{
1 Neste estudo, tratamos especificamente do trabalho remunerado, caracterizado pela venda da mão de obra regulamentada por políticas de Estado que norteiam as relações trabalhistas (Zanelli, Borges-Andrade \& Bastos, 2014).
} 
expressões de gênero (masculina/feminina), das quais derivariam orientações sexuais (hétero/homossexual). Ou seja, há a imposição de uma linearidade/congruência entre sexo biológico, gênero e expressão da sexualidade, que deve ser necessariamente heterossexual, sendo que essas categorias mantêm uma relação de complementaridade umas com as outras (Costa \& Nardi, 2015).

Historicamente, essa norma se estabeleceu para controlar as condutas ditas "normais", baseada em relações de poder, em que a referência está pautada no homem heterossexual, branco, cristão, urbano e de classe média. Todos aqueles que não se encaixam neste padrão são denominados "outros" e que serão definidos em contraponto ao modelo. Por subverterem a linearidade sexo/gênero/expressão da sexualidade heterossexual, homossexuais muitas vezes são tidos como pessoas a margem da sociedade, passíveis de correções (tratamentos médicos, psicológicos e afins) que os trariam de volta à heteronorma ou mesmo discriminações que os tornariam corpos matáveis (Butler, 2003).

Mott (2001) afirma que homossexuais são uma das minorias mais passíveis de discriminação devido ao caráter revolucionário e desestabilizador da harmonia heterossexual na sociedade que os mesmos causam, pois ao contrário dos negros, mulheres, pessoas com deficiência e outras minorias, que são discriminados e estigmatizados pelas suas características físicas e mentais, homossexuais o são pela percepção social de um desvio de conduta moral, que comprometeria seus desempenhos em diversos contextos.

Mas a discriminação não atinge aos gays e lésbicas da mesma forma. Homens gays passam por discriminação, dentre outros motivos, devido ao rompimento com o projeto de masculinidade tradicional disposto na sociedade, enquanto mulheres lésbicas, além de vivenciarem discriminações por romperem com o modelo heterossexual, por terem sua sexualidade reprimida ao longo da história, passam por um tipo de invisibilidade sóciosexual, tendo sua lesbianeidade fetichizada para atender aos desejos masculinos, além de terem que lidar com as desigualdades baseadas em gênero. Ademais, a base das discriminações contra esses sujeitos encontra respaldo nos signos judaico-cristãos dispostos na sociedade ocidental (Louro, 2000).

O termo homofobia é utilizado para a conceitualização da violência e discriminação contra indivíduos homossexuais. O conceito foi inicialmente trabalhado por George Weinberg na década de 1970 e foi definido como o pavor de estar próximo a homossexuais e no caso dos próprios homossexuais, a auto aversão. O conceito objetivava situar a discriminação contra homossexuais no campo médico da patologia, a partir da ideia de fobia. Mas neste estudo, fugindo dos reducionismos essencialistas, o conceito será utilizado como força política para designar o preconceito e discriminação contra pessoas nãoheterossexuais e a tudo que faz alusão a nãoheterossexualidade (Costa \& Nardi, 2015).

Entre os tipos de homofobia, pode-se apontar a institucional, ou seja, formas pelas quais instituições discriminam pessoas em função de sua orientação sexual ou identidade de gênero presumida. E também os crimes de ódio de caráter homofóbico, ou seja, violências, tipificadas pelo código penal brasileiro, cometidas em função da orientação sexual ou identidade de gênero presumida da vítima. A homofobia presente na estrutura da sociedade brasileira vitimiza não apenas a população LGBT $^{* 2}$, cujas oportunidades são limitadas pelo preconceito, mas qualquer indivíduo em que a identidade de gênero seja percebida como diferente da heterossexual, pois ao longo dos

\footnotetext{
${ }^{2}$ Lésbicas, Gays, Bissexuais, Travestis e Transexuais, sigla padronizada na $1^{\circ}$ Conferência Nacional LGBT no ano de 2008 em Brasília. O símbolo “*” tem por objetivo deixar a sigla aberta, para abranger demais identidades possivelmente não contempladas.
} 
anos a homofobia tem se institucionalizado na cultura e na política (Brasil, 2016).

A discriminação contra esse público pode ocorrer de diversas formas e em diversos locais. Uma pesquisa realizada pela Organização das Nações Unidas para a Educação, a Ciência e a Cultura (Unesco) no Brasil, revelou que $25 \%$ dos estudantes pesquisados não gostariam de ter um colega de classe homossexual (resposta majoritariamente emitida por estudantes do sexo masculino) (Castro, Abramovay \& Silva, 2004).

De acordo com Souza, Coelho, Martins e Honorato (2018), a partir de 2011, dados violações de direitos contra LGBTs foram registrados a partir do Disk Direitos Humanos no Brasil (DISK 100), sendo que nesse mesmo ano houve 1159 denúncias, em 2012 foram 3031, em 2013 foram 1695, em 2014 as denúncias somaram 1013, em 2015 foram reportados 1983 denúncias, já em 2016 foram 1876 violações denunciadas e em 2017 a quantidade de denúncias foi de 1720. Os tipos de violações perpassaram por violência física, psicológica, moral, patrimonial e sexual. Os mesmos autores discorrem que o perfil da população LGBT mais vitimizada é de jovens pretos e pardos, do sexo biológico masculino, gays e também pessoas travestis/transexuais.

Vale ainda destacar que o Supremo Tribunal Federal (STF) determinou no dia 13 de junho de 2019, que a discriminação por orientação sexual e identidade de gênero passe a ser considerada um crime no Brasil, determinando que a conduta passe a ser punida pela Lei de Racismo (7716/89), que hoje prevê crimes de discriminação ou preconceito por "raça, cor, etnia, religião e procedência nacional"3.

Ainda assim, com esse avanço no combate a discriminação, de acordo com Gonçalves (2014), não há legislação específica no Brasil para a discriminação no mercado de trabalho baseada em orientação sexual, mas é importante ressaltar que todas as formas de discriminação ou assédio, mesmo que não expressas diretamente, estão contempladas na Consolidação das Leis Trabalhistas (CLT), ou seja, mesmo que não haja especificamente pontos sobre homofobia apontados na CLT, é possível enquadrá-la pela tipologia do crime, tal como assédio moral. $\mathrm{O}$ grande ponto aqui é que as demandas que chegam à justiça do trabalho referentes a essa questão dependem do bom senso e abertura subjetiva a diversidade sexual do operador de direito responsável pelo caso. Tendo essas questões em vista, surgiram as provocações que serviram de motivação para conhecer as discriminações vividas por homossexuais no mercado de trabalho.

Assim, questiona-se: Como a literatura publicada no formato de artigos científicos tem discutido a discriminação vivenciada por homossexuais no mercado de trabalho? O passo a passo da revisão será descrito a seguir.

\section{Metodologia}

Este estudo corresponde a uma revisão bibliográfica integrativa de caráter qualitativo, que consiste em uma ampla análise de literatura, trabalhando com dados teóricos e empíricos, que objetiva compreender um determinado fenômeno a partir de estudos anteriores, a revisar teorias e evidências e a analisar problemas metodológicos, dentre outros, de um tópico particular. A metodologia seguirá o proposto por Whittemore \& Knafl (2005), uma vez que propõem a inclusão tanto de estudos experimentais como não experimentais, mais adequado ao objeto de estudo em questão. Segundo as autoras, a revisão integrativa deve seguir os seguintes passos:

1) Identificação do problema: $\mathrm{O}$ objetivo da pesquisa em uma revisão integrativa facilitará a capacidade de operacionalizar com precisão variáveis e assim extrair dados apropriados de fontes primárias,

\footnotetext{
${ }^{3}$ Disponível em: < https://www.conjur.com.br/2019-jun13/stf-reconhece-criminalizacao-homofobia-lei-racismo . Acesso em 02 de jan. de $2020>$
} 
assim, o objetivo desta revisão é foi compreender a discriminação vivida por homossexuais no mercado de trabalho.

2) O segundo passo corresponde a coleta dos dados, onde toda literatura relevante sobre o tema de análise será incluída. Dessa forma, os passos da coleta neste estudo iniciaram-se na definição dos descritores de busca, sendo "homofobia" e "homossexuais" e "mercado de trabalho" onde todos estes foram validados nos Descritores da Biblioteca Virtual de Saúde (Dec's BVS). Os descritores foram combinados da seguinte forma: "homossexuais $A N D$ mercado de trabalho" e "homofobia AND mercado de trabalho". A base de dados de coleta foi o Portal Periódicos CAPES, a mesma foi escolhida pelo seu caráter integrador no acesso a periódicos científicos no Brasil, sendo um dos principais buscadores de artigos no país, pois o portal engloba diversas bases de dados. A coleta foi realizada entre os dias 5 e 7 de maio de 2020.

Os critérios de inclusão adotados foram: Artigos publicados em revistas indexadas sobre o tema da pesquisa, publicados nas línguas portuguesa, inglesa e espanhola (os descritores foram devidamente traduzidos para espanhol e inglês no momento da coleta), entre janeiro de 2014 a dezembro de 2019, dentro do critério de relevância da base (os 50 primeiros resultados). Utilizamos o critério de relevância da CAPES por conta da grande quantidade de manuscritos presentes no portal, sendo que, devido a problemas de indexação, muitos manuscritos podem não corresponder ao tema deste estudo. Assim, o critério de relevância, ao trabalhar com os 50 resultados mais relevantes (mais citados), nos permitiu uma coleta com melhor qualidade, otimizando o tempo dos autores.

Como critérios de exclusão, removemos outras formas de publicação (artigos de jornal, artigos de anais de eventos, artigos de jornais e outros veículos midiáticos não científicos, livros, dissertações, tese, editoriais, resenhas e afins), artigos publicados fora da temporalidade especificada e em línguas diferentes das já citadas.
Dessa forma, no Portal Periódicos CAPES foram coletados 285 resultados, sendo: a partir da aplicação dos descritores "homofobia e mercado de trabalho" em língua portuguesa emergiram 87 resultados e 50 foram coletados, seguindo o critério de relevância da CAPES. Com os descritores em língua espanhola (La Homofobia y el Mercado Laboral), emergiram 39 resultados e todos foram coletados por estarem dentro do critério de relevância da base. Já com a aplicação dos descritores em língua inglesa (Homophobia and The Labor Market), foram encontrados 845 resultados, onde os 50 primeiros foram colhidos seguindo o critério de relevância da CAPES.

Com a aplicação dos descritores "Homossexuais e o Mercado de Trabalho" em língua portuguesa, emergiram 146 resultados, onde os 50 primeiros foram coletados. Com os descritores em língua espanhola ( $L a$ homossexualidad y el Mercado Laboral), emergiram 46 resultados, todos coletados. Já com a aplicação dos descritores em língua inglesa (Homosexuals and the Labor Market) emergiram 645 resultados, onde os 50 primeiros foram coletados.

3) O terceiro passo correspondeu a avaliação dos dados coletados. Assim, os 285 resultados coletados foram descritos em uma planilha do Microsoft Excel para serem tratados e organizados inicialmente. Dessa maneira, nessa etapa, foram excluídos os resultados que não estavam no formato de artigos científicos, mas que estavam indexados nas bases. Assim, foram excluídos aqui 27 resultados (6 resenhas; 3 livros; 5 artigos de jornal, 1 tese, 8 editoriais e 4 entrevistas). Após, foram excluídos 52 artigos que estavam repetidos na base. Dessa forma, restaram então 206 artigos dos quais foram lidos os títulos e resumos para o terceiro recorte e exclusão daqueles que não apontavam para o objetivo deste trabalho. Nessa etapa, 189 artigos foram excluídos.

4) A quarta etapa diz respeito à análise e interpretação dos dados: Para essa, restaram 17 artigos, os quais passaram por leitura 
completa. Para apoio na leitura, foi elaborado um instrumento, chamado "protocolo de RI", que nos auxiliou na análise descritiva inicial dos artigos. Este protocolo baseia-se no estudo de Evans e Pearson (2001) e conteve: a pergunta da revisão, os critérios de inclusão e as estratégias de busca, assim descritos: i) a identificação (título do artigo, título da revista em que foi publicado o artigo, área do periódico, base de dados, ano e autores e país da publicação); ii) metodologia do estudo; iii) as principais considerações/resultados e pergunta da pesquisa e iv) um campo para que se justifique caso o estudo seja excluído da amostra final. Após a análise, o revisor deu seu parecer de "selecionado" ou "não selecionado" para cada artigo, seguindo o critério de relevância do estudo para a amostra e se o mesmo contemplava a temática proposta de forma integral. Nessa etapa foram excluídos 5 artigos, por não contemplarem o tema deste estudo.

A amostra final desta revisão foi composta então, por 12 artigos e para analisar os dados extraídos destes, foi utilizada a técnica de Análise de Conteúdo. Esse procedimento organiza-se em três fases, segundo Bardin (2011): I) Pré-Análise: É a organização de todos os materiais utilizados na coleta dos dados (correspondente a organização e leitura dos artigos no protocolo). II) Exploração do Material: que consiste nas operações de codificação em função das regras que já foram previamente formuladas (após a leitura no protocolo, criou-se as categorias). III) Tratamento dos resultados: É a fase de análise propriamente dita, onde os resultados brutos serão tratados de maneira a serem significativos (discussão dos dados). A representação da coleta pode ser vista no fluxograma 1, a seguir:

\section{Fluxograma 1}

\section{Coleta de artigos da revisão.}

\begin{tabular}{|c|c|c|c|c|}
\hline $\begin{array}{l}\text { Fase 1: Identificação do } \\
\text { problema }\end{array}$ & \multicolumn{4}{|c|}{$\begin{array}{l}\text { Compreender a discriminação vivida por homossexuais no mercado } \\
\text { de trabalho. }\end{array}$} \\
\hline \multirow{3}{*}{ Fase 2: Coleta de dados } & \multicolumn{4}{|c|}{$\begin{array}{l}\text { Descritores: homofobia/homossexuais/mercado de trabalho } \\
\text { Base de Busca: Portal Periódicos CAPES }\end{array}$} \\
\hline & \multicolumn{2}{|c|}{$\begin{array}{l}\text { Critérios de } \text { Inclusão: Artigos } \\
\text { publicados em revistas } \\
\text { indexadas, publicados nas } \\
\text { línguas portuguesa, inglesa e } \\
\text { espanhola, entre janeiro de } 2014 \\
\text { a dezembro de } 2019 \text {, dentro do } \\
\text { critério de relevância da base (os } \\
50 \text { primeiros resultados). }\end{array}$} & \multicolumn{2}{|c|}{$\begin{array}{l}\text { Critérios de exclusão, outras } \\
\text { formas de publicação (artigos de } \\
\text { jornal, artigos de anais de } \\
\text { eventos, artigos de jornais e } \\
\text { outros veículos midiáticos não } \\
\text { científicos, e afins), artigos fora } \\
\text { da temporalidade especificada e } \\
\text { em outras línguas. }\end{array}$} \\
\hline & \multicolumn{3}{|c|}{$\begin{array}{l}100 \text { artigos } \\
\text { coletados em } \\
\text { português }\end{array}$} & $\begin{array}{l}100 \text { artigos } \\
\text { coletados em } \\
\text { inglês }\end{array}$ \\
\hline $\begin{array}{l}\text { Fase 3: Avaliação inicial } \\
\text { dos dados }\end{array}$ & $\begin{array}{l}27 \text { exclusões: } \\
\text { fora do formato }\end{array}$ & $\begin{array}{l}52 \text { exclusões: } \\
\text { repetidos na } \\
\text { base }\end{array}$ & $\begin{array}{c}189 \\
\text { exclusões: } \\
\text { leitura dos } \\
\text { resumos }\end{array}$ & $\begin{array}{c}5 \text { exclusões: } \\
\text { leitura } \\
\text { completa dos } \\
\text { artigos }\end{array}$ \\
\hline $\begin{array}{l}\text { Fase 4: análise integral } \\
\text { dos artigos }\end{array}$ & \multicolumn{4}{|c|}{12 artigos submetidos a Análise de Consteúdo (Bardin, 2011) } \\
\hline
\end{tabular}

Nota. Revisão da literatura 


\section{Resultados e discussões}

Como resultados, descrevemos a seguir as características de cada artigo selecionado na amostra desta revisão. Quanto ao idioma no qual os artigos foram publicados, 9 foram em língua portuguesa, 3 em língua inglesa e não foi encontrado nenhum artigo em língua espanhola. Quanto aos países das publicações, o Brasil emergiu com 8 publicações, seguido do
Canadá com 2 publicações e após, Portugal e EUA seguiram com uma publicação cada. Quanto aos anos das publicações, 2 artigos foram publicados em 2014, 4 em 2015, 2 em 2016, 3 em 2017, 1 em 2019 e não emergiram publicações dentro das delimitações do estudo no ano de 2018. As áreas dos periódicos foram: Ciências Sociais Aplicadas, Psicologia, Administração, Sociologia e a área Interdisciplinar. O quadro 1, a seguir mostra os artigos analisados:

\section{Quadro 1}

Artigos analisados

\begin{tabular}{|c|c|c|c|}
\hline Artigo & Revista/Ano/Pais & Método & Autores \\
\hline $\begin{array}{c}\text { Homofobia nas organizações e a } \\
\text { legislação aplicada }\end{array}$ & $\begin{array}{l}\text { Revista Borges: Ciências } \\
\text { Sociais Aplicada/ } \\
\text { 2016/Brasil }\end{array}$ & $\begin{array}{l}\text { Revisão } \\
\text { Narrativa }\end{array}$ & $\begin{array}{l}\text { Fabian Artur da Silva e } \\
\text { Adriana Bainha }\end{array}$ \\
\hline $\begin{array}{c}\text { Mercado colorido: percepções de gays } \\
\text { sobre o mercado de trabalho de Teresina- } \\
\text { PI. }\end{array}$ & $\begin{array}{l}\text { Revista Gestão \& } \\
\text { Saúde/2015/Brasil }\end{array}$ & Qualitativo & $\begin{array}{c}\text { Breno Ferreira; Ana } \\
\text { Beatriz Laurindo Souza; } \\
\text { Liliane Leite Moreira } \\
\end{array}$ \\
\hline $\begin{array}{l}\text { Orientação sexual e inclusão: um estudo } \\
\text { de caso em organização varejista de } \\
\text { Fortaleza. }\end{array}$ & $\begin{array}{c}\text { Revista de } \\
\text { Psicologia/2016/Brasil }\end{array}$ & Qualitativo & $\begin{array}{c}\text { Elaine Bastos; Marcelo } \\
\text { Pinheiro; Tereza Cristina } \\
\text { Batista de Lima }\end{array}$ \\
\hline $\begin{array}{l}\text { Homofobia, discriminação e produção de } \\
\text { subjetividades: um estudo com pessoas } \\
\text { homossexuais em empresas do RJ }\end{array}$ & $\begin{array}{c}\text { Revista } \\
\text { Periódicus/2015/Brasil }\end{array}$ & Qualitativo & $\begin{array}{c}\text { Ricardo Henry Dias } \\
\text { Rohm; Samira Loreto } \\
\text { Edilberto Pompeu }\end{array}$ \\
\hline $\begin{array}{c}\text { Trabalho, Violência e Sexualidade: } \\
\text { Estudo de Lésbicas, Travestis e } \\
\text { Transexuais }\end{array}$ & $\begin{array}{c}\text { Revista de Administração } \\
\text { Contemporânea/2014/ } \\
\text { Brasil }\end{array}$ & Qualitativo & $\begin{array}{l}\text { Alexandre de Pádua } \\
\text { Carrieri; Eloisio de Souza; } \\
\text { Ana Camillo Aguiar }\end{array}$ \\
\hline $\begin{array}{l}\text { A vida sexual sob prova: impactos da } \\
\text { vida profissional na construção da } \\
\text { experiência sexual }\end{array}$ & $\begin{array}{l}\text { Sociologia: Problemas e } \\
\text { Práticas/2019/ Portugal }\end{array}$ & Qualitativo & Verónica Policarpo \\
\hline $\begin{array}{l}\text { Sexualidade e trabalho: discriminação e } \\
\text { o preconceito sofrido pelos } \\
\text { homossexuais no ambiente de trabalho }\end{array}$ & $\begin{array}{l}\text { Qualia: a ciência em } \\
\text { movimento/2015/ Brasil }\end{array}$ & $\begin{array}{l}\text { Revisão } \\
\text { Narrativa }\end{array}$ & $\begin{array}{c}\text { Weverton Silva da Costa; } \\
\text { José Calixto de Souza } \\
\text { Pires }\end{array}$ \\
\hline $\begin{array}{c}\text { Discutindo homofobia nas organizações } \\
\text { e no trabalho }\end{array}$ & $\begin{array}{c}\text { Revista Espaço } \\
\text { Acadêmico/2014/ Brasil }\end{array}$ & $\begin{array}{l}\text { Revisão } \\
\text { Narrativa }\end{array}$ & $\begin{array}{c}\text { Henrique Luiz Caproni } \\
\text { Neto; Luciene Aparecida } \\
\text { Fonseca } \\
\end{array}$ \\
\hline $\begin{array}{c}\text { As Crenças sobre a Homossexualidade e } \\
\text { o Preconceito contra Homossexuais no } \\
\text { Ambiente de Trabalho }\end{array}$ & $\begin{array}{c}\text { Temas em } \\
\text { Psicologia/2017/ Brasil }\end{array}$ & Qualitativo & $\begin{array}{l}\text { Annelyse dos Santos Lira } \\
\text { Soares Pereira et al }\end{array}$ \\
\hline $\begin{array}{c}\text { Sexual Prejudice and Labor Market } \\
\text { Outcomes for Gays and Lesbians: } \\
\text { Evidence from Sweden }\end{array}$ & $\begin{array}{l}\text { Feminist Economics/2015/ } \\
\text { EUA }\end{array}$ & Quantitativo & $\begin{array}{l}\text { Autores: Mats } \\
\text { Hammarstedt; Ali M. } \\
\text { Ahmedb; Lina } \\
\text { Anderssonc }\end{array}$ \\
\hline $\begin{array}{c}\text { Sexual Orientation Wage Gaps across } \\
\text { Local Labour Market Contexts: Evidence } \\
\text { from Canadá }\end{array}$ & $\begin{array}{c}\text { Relations industrielles } \\
\text { Industrial Relations/ 2017/ } \\
\text { Canadá }\end{array}$ & Quantitativo & $\begin{array}{l}\text { Nicole Denier; Sean } \\
\text { Waite }\end{array}$ \\
\hline $\begin{array}{l}\text { Sexual Orientation, Labour Earnings, } \\
\text { and Household Income in Canada }\end{array}$ & $\begin{array}{c}\text { Journal of Labor } \\
\text { Research/2017/Canadá }\end{array}$ & Quantitativo & Maryam Dilmaghani \\
\hline
\end{tabular}

Notas. Quadro elaborado pelos autores 
Quanto ao método dos estudos, 6 artigos usaram o método qualitativo, 3 utilizaram o método quantitativo e 3 estudos consistiam em estudos teóricos. Os estudos de cunho quantitativo referiam-se a artigos publicados no Canadá e EUA, onde estudos com esses métodos são muito comuns. No Brasil, os estudos utilizavam predominantemente o método qualitativo, visto a aproximação desse método com as áreas das ciências sociais. Atenção especial a técnica de amostra conhecida como "bola de neve", que esteve presente nos estudos qualitativos como forma de recrutar participantes nas pesquisas. Essa é uma técnica de amostragem não probabilística onde os indivíduos selecionados para a pesquisa convidam novos participantes da sua rede social e a quantidade de participantes vai crescendo na medida em que os indivíduos selecionados convidam novos sujeitos, sendo que o processo pode ser finalizado a partir do atingimento dos objetivos da pesquisa (saturação dos dados). Esta técnica é um método útil para se estudar populações difíceis de serem acessadas ou que não há precisão sobre sua quantidade (Vinuto, 2014). Dessa maneira, ela se mostra assertiva para alcançar a população de homossexuais.

A partir do exposto, nesse momento apresentamos as categorias dos resultados da revisão, a partir da técnica de Análise de conteúdo (Bardin, 2011), devidamente problematizadas com literatura pertinente.

\section{Formas de Discriminação}

Em síntese, os resultados apresentados sugerem que os estereótipos da homossexualidade estão na base do preconceito contra os homossexuais, sendo fatores motivadores de processos discriminatórios no contexto laboral, assim, é sugerido que o mercado de trabalho quase sempre é um lugar hostil aos homossexuais (Pereira, Dia, Lima \& Souza, 2017).

Dos três espaços sociais onde as pessoas desenvolvem sua vida: familiar, social e profissional; é no profissional que a discriminação contra homossexuais se torna mais presente de acordo com Bastos, Pinheiro \& Lima (2016). Dessa forma, o próprio processo de seleção de mão de obra passa pelo crivo da sexualidade, e quando pessoas são percebidas como homossexuais, já nessa etapa elas podem ser segregadas e invisibilizadas (Ferreira, Souza \& Moreira, 2015), visto que muitos gestores não admitem a possibilidade de certos cargos serem preenchidos por homossexuais, ao considerarem que estes poderiam causar "certas influências" nas pessoas, principalmente em crianças (Costa \& Pires, 2015). A isso, alia-se a ideia de que os homossexuais sejam promíscuos e portadores do vírus HIV (Rohm \& Pompeu, 2015).

Esses mesmos sujeitos, quando contratados, geralmente se encontram em posições fragilizadas nas organizações, sendo alvo de várias formas de violências e discriminações no contexto trabalhista como agressões, perseguições, punições por chefes, sabotagem, assédio moral, piadas homofóbicas, bem como pela dificuldade na ascensão profissional, culminando em perdas de promoções, por exemplo, impactando seu trabalho, sua vida pessoal e suas relações, com destaque para as implicações a saúde (Bainha \& Silva, 2016).

A homofobia encontra o meio de expressão o humor (Rohm \& Pompeu, 2015). Por meio de ironia, piadas e anedotas, a discriminação é naturalizada e este instrumento é usado como um sutil instrumento de controle da sexualidade (Pereira et al, 2017). A homossexualidade é tema constante de piadas e pelo uso de palavras que tenham conotação desqualificadora no contexto organizacional onde, consequentemente, o homossexual assumido ou percebido como, é discriminado, principalmente para ocupação hierárquica de cargos mais elevados (Bainha \& Silva, 2016; Carrieri, Souza, \& Aguiar, 2014). Dessa forma, ser identificado como homossexual no ambiente de trabalho pode comprometer a ascensão profissional de um indivíduo (Bastos, Pinheiro \& Lima, 2016), principalmente no setor privado (Dilmaghani, 2018). 
A depreciação de homossexuais no mercado laboral ocorre principalmente através da violência simbólica (Bastos et al., 2016), que, segundo Bourdieu (1989), está presente nos símbolos e signos culturais, especialmente no reconhecimento tácito da autoridade exercida por certas pessoas e grupos. Deste modo, ela muitas vezes não é percebida como violência, mas sim como uma espécie de interdição desenvolvida com base em um respeito que "naturalmente" se exerce de um para outro.

Esse processo é evidenciado quando o ponto de vista heteronormativo é o padrão considerado dominante e natural de modo que o preconceito para com a nãoheterossexualidade atua desqualificando o profissional perante seus colegas, chefes e subordinados, ocorrendo o preterimento profissional, a exclusão e a marginalização do homossexual no ambiente de trabalho (Neto \& Fonseca, 2014).

Assim, não apenas o poder nas empresas é destinado aos heterossexuais, mas quando se trata de um homossexual ou uma pessoa homofóbica sendo cotados para ocupar um cargo de liderança, a homofobia torna-se subliminarmente um critério forte nas decisões (Rohm \& Pompeu, 2015) já que as avaliações do desempenho são fortemente influenciadas, quando a pessoa avaliada é homossexual, por estereótipos morais e preconceituosos (Pereira et al, 2017).

É relatado na literatura a existência de uma barreira invisível em relação ao crescimento na carreira quando se é homossexual (Carrieri et al., 2014) e que a diferença de tratamento no âmbito laboral é observada à medida que não são concedidos direitos e oportunidades compatíveis com aqueles dados aos heterossexuais (Bastos et al., 2016; Costa \& Pires, 2015). Assim, é requerido que homossexuais façam um esforço extra para o treinamento e desenvolvimento de habilidades técnicas no trabalho, para assim terem algum tipo uma vantagem competitiva perante seus pares heterossexuais que, aos olhos da sociedade, estão em vantagem "natural" em relação a homossexuais (Rohm \& Pompeu, 2015).

\section{Discriminações interseccionadas}

As dificuldades em conseguir um emprego ou firmar-se em uma profissão existem para as pessoas que se declaram abertamente homossexuais, mas se intensificam para aquelas que além da sexualidade dissidente, rompem com os estereótipos de gênero (Ferreira et al., 2015). A partir disso, antes de entrarmos na discussão, é importante lançar mão do conceito de gênero.

Para Butler (2003), o gênero não deve ser concebido unicamente como a inscrição cultural de significados em um sexo previamente dado, antes ele é um ato performativo que produz os sexos. Dessa forma, ele não é um fator identitário, mas um ato performativo, estando em mudança constante dependendo da realidade que o cerca. Assim, o papel do gênero seria de produzir a falsa noção de estabilidade do projeto heterossexual e isso se dá a partir do conceito de performatividade, que consiste na imitação quase que compulsória de gestos, atos e signos que reforçam a produção dos corpos masculinos e femininos como os vemos atualmente.

A literatura sugere que há mais dificuldades de homens homossexuais com traços femininos se enquadrarem no mercado de trabalho (Ferreira et al., 2015). A discriminação com o gay que tem traços afeminados existe devido ao modelo de masculinidade tradicional naturalizada pela sociedade, que se baseou em modelos de virilidade que tinham como pressupostos a força física, a potência sexual e o controle do homem sobre a mulher, evidenciados em episódios de violência simbólica e não simbólica que garantiam o domínio masculino na sociedade (Machado, 2016).

O mesmo ocorre com mulheres lésbicas consideradas masculinizadas, com a discriminação misógina (Rohm \& Pompeu, 2015) que tende a ser intensificada para com 
aquelas que possuem menor poder aquisitivo, não possuem a pele de cor branca ou se distanciam de um ideal de estética socialmente valorizado (Neto \& Fonseca, 2014).

Nesse sentido, a vivência de mulheres lésbicas no contexto laboral pode ser compreendida através da interseccionalidade. O conceito foi criado por Kimberle Crenshaw nos anos 1980 para denunciar que mulheres afro-americanas eram atravessadas de um lado pela discriminação de gênero e ao mesmo tempo, por outro lado, pela discriminação racista, assim, a mesma propõe que a interseccionalidade busca articular as dinâmicas de interação entre dois ou mais eixos de opressão (Crenshaw, 2002).

Dessa forma, a literatura sugere que a discriminação no mercado de trabalho encontra-se interseccionada entre gênero (pela não performatividade da masculinidade tradicional) e orientação sexual para homens gays, mas para mulheres lésbicas, a discriminação nesse contexto se mostra na intersecção entre misoginia, discriminação racial e a discriminação homofóbica e de classe. A condição racial associada à homossexualidade torna mais difícil ainda a promoção no trabalho para mulheres homossexuais (Carrieri et al., 2014).

Ademais, perante situações de intolerância nas organizações, muitos homossexuais são forçados a performatizar estereótipos de gênero o mais condizente $o$ possível com o esperado socialmente para o seu sexo para não perderem o emprego (Bainha \& Silva, 2016; Carrieri et al., 2014). Dessa forma, o conceito de homonormatividade pode auxiliar na compreensão desse movimento. De acordo com Oliveira (2013), o conceito diz respeito a uma vivência de gênero performatizada de forma que torne a homossexualidade "aceitável" aos olhos da norma, e isso se faz através de uma progressiva aproximação com os valores e moralidades cultivados pela heteronorma. Assim, é sugerido que o gênero tem a capacidade de "esconder a orientação sexual".
A literatura também sugeriu que homossexuais que performatizam os signos dados como naturais ao seu gênero podem agir com discriminação contra homossexuais que rompem os estereótipos de gênero (Bastos et al., 2016; Ferreira et al., 2015; Carrieri et al., 2014).

Dessa forma, pode-se refletir que a homofobia parte da sociedade em geral direcionada a homossexuais e também pode se manifestar no próprio indivíduo homossexual em direção a si e a outros homossexuais (bem como a tudo o que fizer alusão à homossexualidade ou tudo que é percebido como subversivo a norma heterossexual). Quando manifestada dessa última forma, ela recebe o nome de homofobia internalizada, que se conceitua como uma atitude negativa por parte dos indivíduos homossexuais acerca da sua orientação sexual (Cerqueira-Santos, de Sá, Nunes \& Silveira, 2017). Souza et al. (2018) discutem que homossexuais internalizam o estigma contra a homossexualidade desde tenra idade e isso os prejudica na formação de uma identidade saudável.

\section{A identidade homossexual}

A literatura relata que muitos homossexuais apresentam a necessidade de gerenciamento da sua identidade homossexual, sendo que a principal tática nesse sentido é a ocultação, pois ser "discreto" em relação a essa questão tem fator estratégico (Policarpo, 2019).

Os motivos para esconder sua orientação sexual tem base na tentativa de evitar repressões e resistência por parte da organização (Ferreira et al., 2015). A não revelação da identidade sexual geralmente se dá pela percepção do sujeito de um ambiente hostil a homossexualidade (Rohm \& Pompeu, 2015). Dessa forma, a ocultação da sua identidade sexual aliada a homonormatividade (quando essa identidade já é exposta) são fatores de sobrevivência no mercado de trabalho (Bastos et al., 2016), onde é possível identificar homossexuais que evitam colaborar com grupos de trabalho cujos membros são homossexuais assumidos por medo de serem 
vistos como tal e para evitar manifestar-se contra opiniões homofóbicas de colegas (Policarpo, 2019).

A literatura sugere que as situações de sofrimento se mostraram constantes, em uma espécie de "teatro do trabalho". O teatro se refere aos personagens (considerando trabalhadores que exerçam ou não cargo de chefia, por exemplo), cenário (ambiente interno e externo do trabalho) e aos espectadores (amigos, concorrentes, família). Para homossexuais, esse teatro se transforma em um verdadeiro "drama", por conta de uma sociedade predominantemente heteronormativa (Ferreira et al., 2015).

Os homossexuais acabam levando uma espécie de vida dupla, pois para tentar fugir da opressão da sociedade, acabam por se homonormatizar principalmente em seu ambiente de trabalho, abdicando de certa parte de suas vidas (Costa \& Pires, 2015).

\section{Remuneração}

O homossexual, quando comparado ao heterossexual com a mesma experiência, educação, profissão, estado civil e região de residência, tem mais chances de receber remuneração inferior (Pereira et al, 2017).

Em uma pesquisa específica sobre diferenças salariais baseadas em orientação sexual, Hammarstedt, Ahmed, Andersson (2015) sugeriram que em certa medida, devido a discriminação, homens gays ganhavam menos que homens heterossexuais, enquanto lésbicas ganham aproximadamente o mesmo, ou até mais que mulheres heterossexuais. Os homens gays também apresentaram taxas de emprego mais baixas do que os heterossexuais, enquanto as lésbicas apareceram com taxas de emprego mais altas do que as mulheres heterossexuais.

O emprego e os ganhos relativos dos homens gays são afetados negativamente pelas atitudes públicas negativas em relação aos homossexuais. Quando se trata de lésbicas, as baixas diferenças salariais podem ser explicadas a partir das diferenças entre homossexuais e heterossexuais nas preferências pelo trabalho doméstico versus trabalho de mercado e na sua representação em diferentes tipos de ocupações (Hammarstedt, Ahmed, \& Andersson, 2015), ou seja, mulheres lésbicas são sugeridas como mais orientadas e disponíveis ao mercado de trabalho, enquanto mulheres heterossexuais sofrem exacerbada pressão para cumprir o projeto heterossexual de submissão e cuidados domésticos, familiares e maternos.

Uma pesquisa no Canadá, apontou para uma hierarquia salarial não apenas por gênero, mas também por orientação sexual, com homens heterossexuais ganhando mais que homens gays, que ganham mais que mulheres lésbicas, que são seguidas de mulheres heterossexuais (Denier \& Waite, 2017). Essa hierarquia é percebida principalmente no setor privado do país.

\section{Profissões específicas para gays e lésbicas?}

A literatura sugere que algumas profissões de certo modo, informais e por vezes desvalorizadas socialmente em vários contextos, seriam mais "adequadas" aos homossexuais masculinos com traços femininos, como aquelas de cabeleireiro, maquiador, esteticista e estilista, ou seja, profissões que estão relacionadas ao mundo feminino. Quanto às lésbicas, principalmente quando apresentam um modo de ser associado com a masculinidade, é sugerido que são mais propensas a trabalhar em ocupações orientadas para homens e ocupam posições mais altas que outras mulheres (Dilmaghani, 2018; Neto \& Fonseca, 2014). Aqui temos outro ponto que nos ajuda a entender a diferença salarial baseada em orientação sexual discutida anteriormente.

É discutido que homossexuais podem evitar profissões conservadoras e percebidas como preconceituosas. Dessa forma, gays e lésbicas podem fazer escolhas diferentes em relação à localização de sua residência visto a necessidade de empregabilidade, evitando áreas rurais e sendo mais propensos a se 
deslocar para áreas metropolitanas pela percepção de que esses espaços são mais abertos a diversidade (Hammarstedt et al., 2015; Denier \& Waite, 2017).

Assim, homossexuais assumidos são mais voltados para a carreira profissional que permita expressar a orientação sexual no trabalho, enquanto os homossexuais que não tem sua identidade sexual divulgadas podem focar suas escolhas profissionais fundamentadas em valores de trabalho mais tradicionais e relacionados a status, compromisso e estabilidade (Bastos et al., 2016). Dessa forma, não esconder sua sexualidade no ambiente de trabalho pode ser importante para que se construa uma base de confiança e se tenha uma rede social de apoio no contexto organizacional. Assim evita-se o desgaste em tentar construir uma personalidade contrária à sua sexualidade (Costa \& Pires, 2015).

\section{Inclusão e políticas de gestão da diversidade}

A literatura sugeriu contradições no que diz respeito a ações de inclusão, por parte das empresas, da diversidade no contexto organizacional. É relatado o discurso de aceitação de homossexuais, mas com formas veladas de preconceito, onde a dificuldade de ascensão profissional é percebida (Bastos et al., 2016).

O conceito de inclusão é amplamente utilizado nos contextos da educação especial, mas vale resgatá-lo e problematizá-lo nessa discussão. De acordo com Mantoan (2003), é preciso ter cuidado para que a inclusão não se confunda com a "integração". Para a autora, a integração escolar refere-se à inserção dos alunos com deficiência na escola regular, mas também se dá no agrupamento destes em "escolas especiais" ou "classes especiais" e parte justamente de uma perspectiva de normalização dos corpos, sendo uma inserção parcial por que o sistema prevê serviços educacionais segregados. A inclusão questiona a organização da educação especial e regular e também a integração, pois causa uma mudança no paradigma educacional atual, propondo uma educação plural e que não elimine ou invisibilize as diferenças, mas que as trate como necessárias ao processo de aprendizagem, que se organize para recebê-las e as valorize.

Dessa maneira, quando o mercado de trabalho segrega homossexuais em "profissões específicas", como discutido anteriormente, ou os contrata sem um preparo específico do ponto de vista organizacional, o que é feito é um processo de integração desses corpos devido aos estereótipos da sexualidade, pois incluir, na perspectiva de Mantoan (2003), significaria mudar as estruturas e a cultura organizacional para valorização da diversidade. Diante disso, a literatura tem mostrado que a criação de um ambiente que valorize o/a trabalhador/a homossexual, no entanto, parece ter pouco valor para as empresas, conforme Rohm \& Pompeu (2015).

Diante do contexto apresentado, é sugerido que as políticas de diversidade voltadas para o respeito à diferença sexual no trabalho são escassas nas organizações e não tem atingido seus objetivos sendo a incongruência entre o discurso e a prática um dos aspectos mais enfatizados na literatura, pois geralmente, o discurso de inclusão da diversidade (e nesse caso, especificamente a diversidade sexual) é utilizado como forma da empresa obter legitimidade na sociedade e no mercado, melhorando assim sua imagem, do que de fato como preocupação social (Neto \& Fonseca, 2014).

Por outro lado, organizações que adotam medidas de integração voltadas ao público não heterossexual, a fim de eliminar a exposição de seus trabalhadores ao preconceito e discriminação baseada em orientação sexual, são capazes de motivá-los a dar mais de si para o trabalho, o que proporciona maior identificação com a atividade que realizam e maior dedicação à organização, iniciando um círculo virtuoso (Bainha \& Silva, 2016), pois embora a existência de uma legislação que proíba a discriminação sexual no trabalho seja importante na redução da discriminação, o fator mais relevante para a diminuição da 
discriminação não é a lei, mas a existência de uma cultura organizacional "amigável" em relação aos homossexuais (Pereira et al, 2017).

Dessa forma, em um ambiente em que os membros de todos os grupos são tratados de forma justa e conseguem desenvolver um senso de pertencimento, têm igualdade de oportunidades e são representados em todas as funções e níveis organizacionais, aí sim se estará trabalhando com a inclusão, de acordo com Zanelli, Borges-Andrade \& Bastos (2014) e para isso, a literatura sugere a criação e implementação de políticas de gestão da diversidade.

De acordo com Ferreira, Souza \& Moreira (2015), a gestão da diversidade consiste em administrar as relações de trabalho, as práticas de emprego e a composição interna da força de trabalho, com o objetivo de atrair e reter os melhores talentos dentre os grupos de minoritários da sociedade. Ela amplia a variedade de habilidades, competências e de ideias. A orientação sexual é um conceito com múltiplas interpretações que devem ser absorvidas para uma melhor aceitação dessas diferenças.

Dessa forma, observa-se que a diversidade pode ser tomada sob um olhar mais pragmático, ou seja, poderia traduzir-se em vantagem competitiva para as organizações que a adotassem (Bastos et al., 2016), mas, para que ela funcione de maneira inclusiva, a diversidade precisa ser utilizada de maneira politizada para se promover justiça social e não apenas ser encarada como aspecto de vantagem competitiva e performance e lucro, pois somente assim essas políticas seriam efetivas na redução de níveis de desigualdades e promoveriam a inclusão (Carrieri et al., 2014).

Nesse viés, podemos compreender as políticas de gestão da diversidade como uma forma de biopolítica, conforme discutido por Foucault (1976/2018). O autor discute que até o século XVIII, o poder, que era o poder monárquico, ou seja, era o poder de fazer morrer ou deixar viver, onde o monarca podia interferir diretamente na vida dos súditos. Com o advento do capitalismo industrial e as modificações sociais advindas dele, o autor enxerga a mudança no poder para um fazer viver ou deixar morrer, onde esse fazer viver seriam políticas capazes de promover a vida pois a vida é necessária para manter o capitalismo funcionando ou deixar morrer aquele tipo de vida que não interessa ao poder econômico ou político. Dessa forma, as organizações, como instituições com poder político, quando adotam políticas de gestão da diversidade com base na justiça social, auxiliam na promoção da vida desses sujeitos e na inexistência dessas gestões, o mercado contribui para o deixar morrer desses sujeitos.

\section{Conclusões}

Seguindo para as considerações finais deste estudo, a revisão mostrou que a presença de discriminação contra homossexuais no local de trabalho colabora com a existência no ambiente laboral do que Meyer (2003) denominou de "estresse social minoritário." De acordo como o autor, os membros de um grupo estigmatizado experimentam estressores comuns em maiores intensidades e estressores adicionais e únicos devido a sua condição de minoria sexual e envolve três aspectos: (a) a experiência direta de rejeição ou violência como resultado da orientação sexual, observada nas discriminações com base em humor, baixa possibilidade de ascensão profissional e demais condutas discriminatórias; (b) a construção da própria identidade a partir das atitudes negativas da sociedade em relação à diversidade sexual, que pode fazer com que homossexuais discriminem outros homossexuais no contexto organizacional, principalmente aqueles que rompem com as normas tradicionais de gênero; (c) a antecipação do preconceito, que está associada, por exemplo, a ocultação da orientação sexual no trabalho, tida no medo de ser discriminado e na adoção de uma postura o mais "discreta" o possível no que diz respeito a esse assunto.

As discriminações acompanham a trajetória do profissional homossexual desde o processo de seleção, na convivência com os pares na empresa, nas avaliações de 
desempenho e na ascensão profissional e remuneração, até empurrá-los a profissões estereotipadas de acordo com a não performatividade de gênero. Enquanto isso, o discurso de inclusão da diversidade sexual nos contextos organizacionais mostra como o capitalismo pode se apropriar dos movimentos sociais para ter lucro enquanto nada faz por eles.

As discriminações foram relatadas na literatura de maneira interseccionadas, ou seja, a discriminação baseada em orientação sexual se alia a outras opressões sociais como o racismo, a classe, o gênero e assim por diante. Foi apontado que devido a discriminação, pessoas homossexuais são empurradas para profissões informais e desvalorizadas socialmente, principalmente os homens gays que rompem com as normas de gênero.

Metodologicamente, a literatura analisada foi em sua maioria publicada no Brasil (muito provavelmente por limitações do portal onde os estudos foram colhidos), de cunho qualitativo que utilizavam a técnica de entrevista, com especial atenção a técnica de "bola de neve", que se mostrou assertiva para encontrar os sujeitos. A literatura internacional se mostrou predominantemente quantitativa utilizando dados indiretos (dados de dossiês e documentos oficiais dos países).

Ademais, o estudo se limitou a estudos especificadamente sobre a experiência homossexual no mercado de trabalho. Apesar de alguns artigos trazerem certa experiência de pessoas transgêneras, este estudo não focou nesse público por entendermos que as experiências de pessoas transgêneras merecem atenção específica, portanto, os dados observados sobre esse público devem ser feitos em um estudo à parte. Outro ponto importante é que por mais que tenhamos utilizado a interseccionalidade como balizador de análises, entendemos que a experiência de raça, da mesma forma que as transgeneridades, merece atenção específica. Por fim, a partir dos achados, espera-se que este estudo sirva de base para outras pesquisas sobre a experiências de pessoas não-heterossexuais no mercado de trabalho.

\section{Referências}

Bainha, A., \& Silva, F. A. (2016). Homofobia nas organizações e a legislação aplicada. Revista Borges: estudos contemporâneos em Ciências Sociais e Aplicadas, 6(1), 5069. Recuperado de https://www.revistaborges.com.br/index.ph $\mathrm{p} /$ borges/article/view/109

Bardin, L. (2011). Análise de conteúdo. São Paulo: Edições 70.

Bastos, E. M., Pinheiro, M. S., \& de Lima, T. C. B. (2016). Orientação sexual e inclusão: um estudo de caso em organização varejista de Fortaleza. Revista De Psicologia, 7(1), 165-180. Recuperado de http://periodicos.ufc.br/psicologiaufc/article /view/6472

Bourdieu, P. (1989). O poder simbólico. Lisboa: Difel.

Brasil. (2016). Relatório de Violência Homofóbica no Brasil: ano 2013.
Secretaria Especial de Direitos Humanos do Ministério das Mulheres, da Igualdade Racial e dos Direitos Humanos. Brasília. Recuperado de http://www.direito.mppr.mp.br/arquivos/Fil e/RelatorioViolenciaHomofobicaBR2013.p $\underline{\mathrm{df}}$

Butler, J. (2003). Problemas de gênero: feminismo e a subversão da identidade. Rio de Janeiro: Civilização Brasileira.

Carrieri, A. de P., Souza, E. M. de, \& Aguiar, A. R. C. (2014). Trabalho, violência e sexualidade: estudo de lésbicas, travestis e transexuais. Revista de Administração Contemporânea, 18(1), 78-95. doi: 10.1590/S1415-65552014000100006

Castro, M. G., Abramovay, M. \& Silva, L. B. (2004). Juventude e sexualidade. Brasília: UNESCO Brasil. 
Cerqueira-Santos, E., de Sá, C. A. G. C., Nunes, L. M. \& Silveira, A. P. (2017). Homofobia internalizada e religiosidade entre casais homoafetivos. Temas em Psicologia, 25(2), 691-702. doi: 10.9788/TP2017.2-15

Costa, Â. B. \& Nardi, H. C. (2015). Homofobia e preconceito contra diversidade sexual: debate conceitual. Temas psicol., 23(3), 715-726. doi: $\underline{10.9788 / T P 2015.3-15}$

Costa, W. S. \& Pires, J. C. de S. (2015). Sexualidade e trabalho: discriminação e o preconceito sofrido pelos homossexuais no ambiente de trabalho. Qualia: a ciência em movimento, 1(1), 78-115. Recuperado de https://revistas.unifan.edu.br/index.php/Rev istaICSA/article/view/126

Crenshaw, K. (2002). Documento para o encontro de especialistas em aspectos da discriminação racial. Revista de Estudos Feministas, 10(1), 171-187. doi: 10.1590/S0104-026X2002000100011

Denier, N. \& Waite, S. (2017). Sexual Orientation Wage Gaps across Local Labour Market Contexts: Evidence from Canadá. Relations industrielles/Industrial Relations, 72(4), 734-762. doi: 10.7202/1043174ar

Dilmaghani, M. (2018). Sexual Orientation, Labour Earnings, and Household Income in Canada. J Labor Res. 39, 41-55. doi: 10.1007/s12122-017-9249-4

Evans, David, \& Pearson, Alan. (2001). Systematic reviews: gatekeepers of nursing knowledge. Journal of Clinical Nursing, 10(5), 593-599. doi: 10.1046/j.13652702.2001.00517.x

Ferreira, B. de O., Souza A. B. L., \& Moreira L. L. (2015). "Mercado colorido": percepções de gays sobre o mercado de trabalho de Teresina-PI. Rev. G\&S, 6(2), 1565-1584. Recuperado de https://periodicos.unb.br/index.php/rgs/artic le/view/2966

Foucault, M. (2018). História da sexualidade 1: a vontade de saber. 7 ed. Rio de Janeiro/São Paulo: Paz e Terra. (Obra original publicada em 1976).
Gonçalves, L. K. (2014). A discriminação por orientação sexual nas relações de trabalho. Cadernos da Escola Judicial do TRT da $4^{a}$ Região, (8), 15-27. Recuperado de https://www.trt4.jus.br/portais/media/43213 5/CadernoEJ-n.08-2014.pdf

Hammarstedt, M., Ahmed, A. M. \& Andersson, L. (2015). Sexual Prejudice and Labor Market Outcomes for Gays and Lesbians: Evidence from Sweden. Feminist Economics, 21(1), 90-109. doi: 10.1080/13545701.2014.937727

Louro, G. L. (2000). O corpo educado: pedagogias da sexualidade (3. ed.). Belo Horizonte: Autêntica.

Machado, B. F. (2016). Estudos de masculinidades: a crise masculina, a masculinidade hegemônica e a paternidade em Onde estão os ovos?, de Fabrício Carpinejar. Mosaico, 7(11), 49-63. doi: 10.12660/rm.v7n11.2016.64777

Mantoan, M. T. E. (2003). Inclusão escolar: o que é? por quê? como fazer?. São Paulo: Moderna.

Martins, J. C. de O. \& Pinheiro, A. de A. G. (2006). Sofrimento psíquico nas relações de trabalho. Psic,7(1), 79-85. Recuperado de http://pepsic.bvsalud.org/scielo.php?script= sci_arttext\&pid=S1676$73142006000100010 \& \operatorname{lng}=\mathrm{pt} \& \mathrm{t} \operatorname{lng}=\mathrm{pt}$

Meyer, I. H. (2003). Prejudice, social stress, and mental health in lesbian, gay, and bisexual populations: conceptual issues and research evidence. Psychol Bull, 129(5), 674-697. doi: 10.1037\%2F00332909.129.5.674

Mott, L. (2001). A revolução homossexual: o poder de um mito. Revista USP, (49), 4059. doi: 10.11606/issn.23169036.v0i49p40-59

Neto, H. L. C. \& Fonseca, L. A. (2014). Discutindo homofobia nas organizações e no trabalho. Revista Espaço Acadêmico, 14(161), 1-10. Recuperado de http://www.periodicos.uem.br/ojs/index.ph p/EspacoAcademico/article/view/24588

Oliveira, J. M. de. (2013). Cidadania sexual sob suspeita: uma meditação sobre as fundações homonormativas e neo-liberais de uma cidadania de 
"consolação". Psicologia \&

Sociedade, 25(1), 68-78. doi:

10.1590/S0102-71822013000100009

Pereira, A. dos S. L. S., Dia, S. M. P. da S., Lima, T. J. S. de, \& Souza, L. E. C. de. (2017). As crenças sobre a homossexualidade e o preconceito contra homossexuais no ambiente de trabalho. Temas em Psicologia, 25(2), 563575. doi: 10.9788/TP2017.2-10

Pereira, C. de S., Del Prette, A., \& Del Prette, Z. A. P. (2008). Qual o significado do trabalho para as pessoas com e sem deficiência física?. Psico-USF, 13(1), 105114. doi: 10.1590/S1413$\underline{82712008000100013}$

Policarpo, V. (2019). A vida sexual sob prova: impactos da vida profissional na construção da experiência sexual. Sociologia, Problemas e Práticas, (89),133-157. doi: 10.7458/SPP2019899958

Rohm, R. H. D. \& Pompeu, S. L. E. (2015). Homofobia, discriminação e produção de subjetividades: um estudo com pessoas homossexuais em empresas do Rio de Janeiro. Periódicus, 3(1), 228-246.

Recuperado de https://periodicos.ufba.br/index.php/revista periodicus/article/view/14262

Rubin, G. (2003). Pensando sobre sexo: notas para uma teoria radical da política da sexualidade. Brasil: Mimeo
Silva, N. \& Tolfo, S. da R. (2012). Trabalho significativo e felicidade humana: explorando aproximações. Revista Psicologia Organizações e Trabalho, 12(3), 341-354. Recuperado de http://pepsic.bvsalud.org/scielo.php?script= sci_arttext\&pid=S1984$\underline{66572012000300008 \& \operatorname{lng}=p t \& t \operatorname{lng}=p t}$

Souza, D. C. de, Coelho, I. M., Martins, F. dos S., \& Honorato, E. J. S. (2018).

Assassinatos de LGBTs no Brasil - uma análise de literatura entre 2010-2017. Periódicus, 10(1), 24-39. Recuperado de https://periodicos.ufba.br/index.php/revista periodicus/article/view/27919

Vinuto, J. (2014). A amostragem em bola de neve na pesquisa qualitativa: um debate em aberto, Temáticas, 22(44), 203-220. doi: 10.20396/tematicas.v22i44.10977

Whittemore, Robin \& Knafl, Knalf. (2005). The integrative review: updated methodology. Journal of Advanced Nursing, 52(5), 546-553. doi: 10.1111/j.1365-2648.2005.03621.x

Zanelli, J. C., Calzaretta, A. V., García, A. J., Lipp, M. E. N., \& Chambel, M. J. (2010) Estresse nas organizações de trabalho: compreensão e intervenção baseadas em evidências. Porto Alegre: Artmed.

Zanelli, J. C., Borges-Andrade, J. E., \& Bastos, A. V. (2014). Psicologia, organizações e trabalho no Brasil. Porto Alegre: Artmed. 


\section{Dados sobre os autores:}

- Daniel Cerdeira de Souza: Psicólogo, especialista em terapia cognitivo comportamental, pósgraduando em psicologia social, mestre em psicologia e processos psicossociais (UFAM), doutorando em psicologia social e cultura (UFSC).

- Eduardo Jorge Sant'Ana Honorato: Psicólogo, Doutor em Saúde Pública - Saúde da Criança e da Mulher, com ênfase em Sexualidade, Reprodução, Gênero e Saúde, pela Fiocruz (IFF-RJ). Professor Adjunto na Escola Superior de Ciências da Saúde - (ESA/UEA). Professor no Programa de Mestrado Profissionalizante em Saúde da Família (Abrasco-Fiocruz).

- Adriano Beiras: É graduado e licenciado em Psicologia pela Universidade Federal de Santa Catarina (UFSC). Mestre em Psicologia por esta mesma instituição (UFSC), Doutor Europeu em Psicologia Social pela Universidade Autônoma de Barcelona (UAB), Espanha (com Menção Doutor Europeu), revalidado pela UFSC, no Brasil. Professor Adjunto do Departamento de Psicologia da Universidade Federal de Santa Catarina (UFSC). Professor do Programa de Pós-graduação em Psicologia da UFSC, onde coordena a Área 2 - Psicologia Social e Cultura. 